\title{
Neurosensory recovery after trauma to the orbital floor: a prospective trial with dexamethasone
}

\author{
A. Haapanen ${ }^{\mathrm{a}, *}$, H. Thorén ${ }^{\mathrm{b}, \mathrm{c}}$, S. Apajalahti ${ }^{\mathrm{d}}$, A.L. Suominen ${ }^{\mathrm{e}}$, J. Snäll ${ }^{\mathrm{a}}$ \\ a Department of Oral and Maxillofacial Diseases, University of Helsinki and Helsinki University Hospital, Helsinki, Finland \\ b Department of Oral and Maxillofacial Surgery, Institute of Dentistry, University of Turku, Finland \\ c Department of Oral and Maxillofacial Diseases, Turku University Hospital, Finland \\ d Department of Oral and Maxillofacial Diseases, University of Helsinki and Helsinki University Hospital Medical Imaging Center, Helsinki, Finland \\ e Department of Oral and Maxillofacial Surgery, Kuopio University Hospital and University of Eastern Finland, Institute of Dentistry, Kuopio, Finland
}

Received 30 January 2018; accepted 31 August 2018

Available online 13 September 2018

\begin{abstract}
Our aims were to document the occurrence of neurosensory disturbances of the infraorbital nerve six months after operation for an orbital blow-out fracture, and to find out whether dexamethasone facilitates neurosensory regeneration. Patients were randomly assigned to one of two groups: the study group was given a total of dexamethasone $30 \mathrm{mg}$, whereas the control group were given neither glucocorticoid nor placebo. Each patient's infraorbital neurosensory state was recorded preoperatively, immediately postoperatively, and six months later. A total of 18 patients were included, eight of whom had neurosensory disturbances six months after the initial trauma that was not affected by dexamethasone. Six of the seven patients who had a delay of seven days or more between trauma and operation had significantly prolonged disturbance at the 180-day clinical follow up compared with those in whom it was less than seven days $(p=0.005)$. Other possible predictors made no significant difference. Although dexamethasone did not facilitate sensory recovery, its benefits in the management of pain and reduction of swelling may justify its use in the management of facial trauma in selected patients.
\end{abstract}

(C) 2018 The British Association of Oral and Maxillofacial Surgeons. Published by Elsevier Ltd. All rights reserved.

Keywords: Neurosensory disturbance; orbital fracture; dexamethasone; facial trauma

\section{Introduction}

Orbital fractures often cause transient neurosensory disturbance of the infraorbital nerve (ION), and reported rates vary between $11 \%$ and $35 \%$ depending on the site and type of orbital fracture. ${ }^{1-3}$ Retrospective studies have reported that long-term neurosensory disturbance persists in $9.3 \%-55 \%$ of patients who have had orbital operations. ${ }^{2-4}$ At worst, chronic pain may develop in the ION, which can result in problems in

\footnotetext{
* Corresponding author at: Department of Oral and Maxillofacial Diseases, Helsinki University Hospital, 00029 HUH, Finland. Tel.:+358 40 7251598.

E-mail address: aleksi.haapanen@ @elsinki.fi (A. Haapanen).
}

daily life, clinical depression, and the need for antidepressant medication. $^{5}$

Previously published surveys have suggested that the use of perioperative glucocorticoids is common among surgeons who do craniomaxillofacial procedures, ${ }^{6,7}$ the most commonly reported reasons being to reduce postoperative oedema and pain. For orbital fractures in particular, results of randomised studies have supported the use of glucocorticoids to reduce postoperative swelling ${ }^{8}$ and pain ${ }^{9}$ in selected patients, and animal studies have shown that glucocorticoids also have the potential to facilitate recovery of the nerve. ${ }^{10}$ However, we know of no study of the effects of glucocorticoids on recovery from neurosensory disturbance of the ION associated with an orbital fracture. 
Our aims, therefore, were to document the occurrence of neurosensory disturbance of the ION six months after operation for a fracture of the orbital floor, and to find out whether dexamethasone given perioperatively improves its recovery. Our hypothesis was that dexamethasone improves recovery from neurosensory disturbance.

\section{Patients and methods}

\section{Design of the study}

The present study is part of a larger study of patients with facial fractures who participated in a single-blind, randomised study, the purpose of which was to clarify the benefits and drawbacks of dexamethasone given perioperatively. ${ }^{11}$ Patients were recruited between 1 June 2006 and 31 December 2010, and were eligible for inclusion if they were at least 18 years old and were to have one of the following three procedures: treatment of mandibular fractures (one or two fractures in the dentate area) with titanium miniplates; open reduction and miniplate fixation of a unilateral zygomatic complex fracture; or reconstruction of a fracture of the orbital floor. Patients with infected fractures; who had a history of liver or kidney dysfunction, peptic ulcer, or psychosis resulting from the use of steroids; and those who were pregnant, breastfeeding, or were allergic to any constituent of the dexamethasone preparation used, were excluded.

Patients were randomly assigned to one of two groups. Those in the study group were given dexamethasone (Oradexon ${ }^{\circledR}$ ), while those in the control group were given neither a glucocorticoid or a placebo. The study group were given dexamethasone $10 \mathrm{mg}$ intravenously during induction of anaesthesia, and an additional $10 \mathrm{mg}$ intramuscularly into either the deltoid or gluteal muscle every eight hours over 16 hours (total dose $30 \mathrm{mg}$ ). The different procedures (mandibular, zygomatic, and orbital) were randomised separately using sealed envelopes. Patients included in the present analysis had previously been randomised to have repair of the orbital floor, and had either preoperative or postoperative neurosensory disturbance in the ipsilateral ION.

Propofol was used to induce anaesthesia, which was maintained with sevoflurane or desflurane. Fentanyl was used to manage pain during operation, and paracetamol and oxycodone hydrochloride were used postoperatively.

\section{Study variables}

The primary outcome variable was recovery of the neurosensory disturbance during the first six months postoperatively, and the primary predictor was the use of perioperative dexamethasone. Other predictive variables included were age, sex, duration of time between accident and operation, maximum displacement of the orbital floor, maximum displacement of the ION, and the anteroposterior depth of the fracture. Sensation in the ION was tested clinically with touch and pinprick in the trigeminal areas of skin and mucosa.

All patients had a multislice computed tomographic (CT) examination preoperatively. The data were reformatted into coronal, axial, and sagittal images 1.0 or $1.5 \mathrm{~mm}$ thick, and reformatted images as parasagittal to orbit. The fractures were classified into separate orbital floor fractures or fractures that also involved the medial orbital wall. In addition, the maximum displacement of the orbital floor $(\mathrm{mm})$ and that of the $\mathrm{ION}$ were measured. The area $\left(\mathrm{mm}^{2}\right)$ of the fracture was measured from coronal images by multiplying the diameter of the bony defect in the orbital floor by the thickness of the slice. A zone-qualification was used to assess the horizontal depth of the fracture and the zones were divided into three depending on the maximum depth, as described by Jaquiery et $\mathrm{al}^{12}$ CT data were analysed twice by an experienced radiologist to secure the measurements by intrainvestigator correlation.

\section{Statistical analysis}

Chi squared tests were used to assess the significance of differences in associations between the development of postoperative neurosensory disturbance and the perioperative use of dexamethasone, sex, age ( $<50$ or 50 or more years), use of dexamethasone, duration of time between trauma and operation ( $<7$ or 7 or more days), maximum displacement of the orbital floor, maximum displacement of the ION, and the anteroposterior depth of the fracture.

\section{Ethics approval}

The study was approved by the Research Ethics Board of the Department of Surgery and the Internal Review Board of the Division of Musculoskeletal Surgery, Helsinki University Central Hospital, Finland (Dno 33/E6/06).

\section{Results}

A total of 27 patients with an isolated unilateral orbital floor fracture with or without medial wall fracture were invited to participate in the primary study, but three patients refused. Of the remaining 24, three were excluded from analysis because one did not have neurosensory disturbance either preoperatively or postoperatively, one required reoperation, and one did not receive all three doses of dexamethasone. Of the remaining 21 patients, three were lost to follow-up.

Details of the 18 remaining patients are shown in Table 1, and the associations between neurosensory disturbance and the predictors six months postoperatively are shown in Table 2. Our hypothesis that dexamethasone improves recovery was not confirmed. The only significant predictor six months postoperatively was a time of $\geq 7$ days from trauma to operation $(\mathrm{p}=0.005)$. 
Table 1

Details of 18 patients with orbital blow-out fractures and neurosensory disturbance of the infraorbital nerve. Data are number of patients unless otherwise stated.

\begin{tabular}{ll}
\hline Variable & Value \\
\hline Median (range) age (years) & $50(23-81)$ \\
Sex: male/female & $9 / 9$ \\
Median (range) time from accident to operation (days) & $6(3-19)$ \\
$\begin{array}{l}\text { Neurosensory disturbance diagnosed: } \\
\text { preoperatively/postoperatively }\end{array}$ & $16 / 2$ \\
$\begin{array}{l}\text { Overall median (range) maximum radiological } \\
\quad \text { displacement (mm) }\end{array}$ & $10(1-33)$ \\
$\begin{array}{l}\text { Median (range) maximum radiological displacement of } \\
\quad \text { nerve (mm) }\end{array}$ & $3.5(0-10)$ \\
Maximum zones: $1 / 2 / 3$ & $2 / 9 / 7$ \\
Dexamethasone given: yes/no & $10 / 8$ \\
\hline
\end{tabular}

\section{Discussion}

Our aims were to document the occurrence of neurosensory disturbance of the ION six months after operation for a fracture of the orbital floor, and to test whether dexamethasone given perioperatively improves recovery.

Our results are consistent with our previous observations in patients with zygomatic fractures, in whom there was no significant difference between patients treated with dexamethasone and controls. ${ }^{13}$ Studies that focused on the effects of glucocorticoids in orthognathic surgery showed similar results. ${ }^{14,15}$ The pertinent published papers have suggested that the main benefits of using glucocorticoids in association with facial fractures are a reduction in both postoperative oedema ${ }^{8,14,15}$ and pain. ${ }^{9}$ However, patients should be selected carefully, as glucocorticoids may disturb wound healing. ${ }^{16}$ Interestingly, we found that $8 / 18$ patients who attended the six-month clinical follow up had neurosensory disturbances. This is lower than in our previous study on ION in fractures of the zygomatic complex, where 29/45 of the patients still had neurosensory disturbances six months postoperatively. ${ }^{13}$ The type of primary trauma to the nerve (pinching, laceration, or traction) probably has a key role in the recovery of the nerve.

Further studies of actual nerve damage should be designed to differentiate between which part of the neurosensory disturbance is caused by the initial trauma and which is a consequence of the operation. Follow-up should be extended to 18 months to find out if the disturbance is permanent.
Fractures of the orbital floor and the operations to deal with them vary, and this also causes variations in the rate of neurosensory recovery. Although this variation cannot be fully controlled, it can be considered to be a limitation in this study, as the size of the sample was limited. A multivariate analysis would be the gold standard to assess the relative importance of predictors, but our sample size limited these possibilities.

Although dexamethasone did not facilitate sensory recovery, its benefits in the management of pain and the reduction of swelling may justify its use in the management of facial trauma in selected patients.

\section{Conflict of interest}

We have no conflicts of interest.

\section{Ethics statement/confirmation of patients' permission}

The study protocol was approved by the Ethics Committee of the Department of Surgery and the Internal Review Board of the Division of Musculoskeletal Surgery, Helsinki University Hospital, Finland (Dno 33/E6/06) and registered at Helsinki University Hospital, Helsinki, Finland under identification number HUS2325. All procedures were in accordance with the ethical standards of the institutional research committee and with the 1964 Declaration of Helsinki and amendments thereafter. Informed consent was obtained from all participants.

\section{References}

1. Takahashi Y, Sabundayo MS, Miyazaki H, et al. Orbital trapdoor fractures: different clinical profiles between adult and paediatric patients. $\mathrm{Br}$ J Ophthalmol 2018;102:885-91.

2. Choi WK, Kim YJ, Nam SH, et al. Ocular complications in assault-related blowout fracture. Arch Craniofac Surg 2016;17:128-34.

3. Hwang K, Hwang JH. Do we have to dissect infraorbital nerve from periorbita in orbital floor fracture? J Craniofac Surg 2009;20:1260-2.

4. Folkestad L, Westin T. Long-term sequelae after surgery for orbital floor fractures. Otolaryngol Head Neck Surg 1999;120:914-21.

5. Beigi B, Beigi $\mathrm{M}$, Niyadurupola $\mathrm{N}$, et al. Infraorbital nerve decompression for infraorbital neuralgia/causalgia following blowout

Table 2

Association between neurosensory disturbance and predictors six months after operation.

\begin{tabular}{|c|c|c|c|}
\hline Variable & $\begin{array}{l}\text { Neurosensory } \\
\text { disturbance }(n=8)\end{array}$ & $\begin{array}{l}\text { No neurosensory } \\
\text { disturbance }(n=10)\end{array}$ & $\mathrm{p}$ value \\
\hline Dexamethasone Yes/no & $5 / 3$ & $5 / 5$ & 0.596 \\
\hline Age (years): $<50 / 50$ or more & $4 / 4$ & $5 / 5$ & 1.00 \\
\hline Sex: male/female & $3 / 5$ & $6 / 4$ & 0.343 \\
\hline Time from accident to operation (days): $<7 / 7$ or more & $2 / 6$ & $9 / 1$ & 0.005 \\
\hline Overall maximum radiological displacement $(\mathrm{mm}):<10 / 10$ or more & $5 / 3$ & $3 / 7$ & 0.168 \\
\hline Maximum radiological displacement of nerve $(\mathrm{mm}): 1$ or less $/ 2-4 / 5$ or more & $4 / 2 / 2$ & $3 / 4 / 3$ & 0.671 \\
\hline Maximum zones: $1 / 2 / 3$ & $2 / 4 / 2$ & $0 / 5 / 5$ & 0.201 \\
\hline
\end{tabular}


orbital fractures: A case series. Craniomaxillofac Trauma Reconstr 2017; 10:22-8.

6. Kormi E, Snall J, Tornwall J, et al. A survey of the use of perioperative glucocorticoids in oral and maxillofacial surgery. J Oral Maxillofac Surg 2016;74:1548-51.

7. Assimes TL, Lessard ML. The use of perioperative corticosteroids in craniomaxillofacial surgery. Plast Reconstr Surg 1999;103:313-22.

8. Flood TR, McManners J, el-Attar A, et al. Randomized prospective study of the influence of steroids on postoperative eye-opening after exploration of the orbital floor. Br J Oral Maxillofac Surg 1999;37:312-5.

9. Kormi E, Snall J, Koivusalo AM, et al. Analgesic effect of perioperative systemic dexamethasone on blowout fracture surgery. J Oral Maxillofac Surg 2017;75:1232-7.

10. Al-Bishri A, Dahlin L, Sunzel B, et al. Systemic betamethasone accelerates functional recovery after a crush injury to rat sciatic nerve. J Oral Maxillofac Surg 2005;63:973-7.

11. Haapanen A, Thoren H, Tornwall J, et al. Postoperative nausea and vomiting in facial fracture patients: a randomized and controlled trial on the effect of dexamethasone. Int J Oral Maxillofac Surg 2017;46:1267-70.
12. Jaquiery C, Aeppli C, Cornelius P, et al. Reconstruction of orbital wall defects: critical review of 72 patients. Int J Oral Maxillofac Surg 2007;36:193-9.

13. Haapanen A, Thoren H, Apajalahti S, et al. Does dexamethasone Facilitate neurosensory function regeneration after zygomatic fracture? A randomized controlled trial. J Oral Maxillofac Surg 2017;75:2607-12.

14. Widar F, Kashani H, Alsen B, et al. The effects of steroids in preventing facial oedema, pain, and neurosensory disturbances after bilateral sagittal split osteotomy: a randomized controlled trial. Int J Oral Maxillofac Surg 2015; $\mathbf{4 4 : 2 5 2 - 8 .}$

15. de Lima VN, Lemos CAA, Faverani LP, et al. Effectiveness of corticoid ddministration in orthognathic surgery for edema and neurosensorial disturbance: a systematic literature review. J Oral Maxillofac Surg 2017;75, 1528.e1-1528.e8.

16. Snall J, Kormi E, Koivusalo AM, et al. Effects of perioperatively administered dexamethasone on surgical wound healing in patients undergoing surgery for zygomatic fracture: a prospective study. Oral Surg Oral Med Oral Pathol Oral Radiol 2014;117:685-9. 